by $\alpha$ - $\alpha^{\prime}$-dipyridyl with various metal ions, has shown that the enzyme systems in the insect Corcyra cephalonica St., pigeon liver and chick kidneys are reactivated by $\mathrm{Fe}^{++}$, that in $A$. niger by $\mathrm{Mg}^{++}$and the one in $N$. crassa by $\mathrm{Mn}++$.

The detection and purification of a stereo-specific dihydrolipoic acid dehydrogenase formed the subjectmatter of an interesting paper by D. K. Basu and D. P. Burma, of the Bose Institute, Calcutta. The enzyme, which was purified 60-70-fold, was found to be diphosphopyridine nucleotide-linked and specific for dihydrolipoic acid and its amide. The reaction was irreversible when tested with lipoic acid as the substrate. I. S. Bhatia and co-workers, of the Tocklai Experimental Station, Cinnemara, Assam, gave an account of their work on the transglycosidase present in tea leaves. This enzyme reacted with maltose with the formation of maltotriose, maltotetrose and glucose. With arabinose as the acceptor of glucosyl residues and maltose as the donor, a disaccharide containing glucose and arabinose was formed.

The purification and properties of glutamicoxalacetic transaminase from ox brain and from human brain were described by T. N. Pattabhiraman and B. K. Bachhawat, of the Christian Medical College, Vellore. A 30-40-fold purification of the enzyme was achieved by fractionating the initial extract with alcohol, $\mathrm{Zn}++$ and ammonium sulphate. The purified ox-brain transaminase showed complete dependence on pyridoxal phosphate for its activity.

A new type of enzymatic transamination reaction in which glyoxylate transaminates with a number of amino-acids to produce glycine was reported by L. V. S. Sastry and T. Ramakrishnan (Indian Institute of Science). Isonicotinic acid hydrazide and $\mathrm{L}$ penicillamine at low concentrations inhibited the enzyme but the inhibition was reversed by pyridoxal phosphate or metal. The authors adduced unequivocal evidence to show that the transaminase was a metallo-enzyme. The purification and properties of a naturally occurring inhibitor of glutamine synthesis present in Pongamia galls was described by N. K. Sukanya and C. S. Vaidyanathan (Indian Institute of Science); they also showed the preponderance of this inhibitor in the gall tissue, as compared to normal tissue.

N. Appaji Rao, H. R. Cama and S. A. Kumar (Indian Institute of Science) gave details of some of their recent work on the occurrence of flavin nucleotides in plants and the changes in their concentration with germination of green gram (Phaseolus radiatus) and cow pea (Vigna catiang). The radicle of the germinating seedlings contained almost all the flavin adenine dinucleotide and the major portion of the total flavin, while the cotyledons and the plumules contained flavin mononucleotide as the major flavin. Some interesting examples of species specificity in the mechanism of pyridine nucleotide synthesis by erythrocytes were reported by $P$. G. Tulpule, of the Nutrition Research Laboratories, Hyderabad. Of the seven species studied by them only human and guinea pig erythrocy tes were capable of synthesizing diphosphopyridine nucleotide from nicotinamide and glucose. Human as well as monkey erythrocytes could also synthesize appreciable amounts of diphosphopyridine nucleotide from nicotinic acid and glucose in the presence of glutamine, whereas this metabolic pathway did not seem to operate in the guinea pig. Red blood cells of the monkey were able to synthesize diphosphopyridine nucleotide only in the presence of glutamine, suggesting that nicotinamide was converted to nicotinic acid prior to incorporation in diphosphopyridine nucleotide.

Four special lectures were given in the evenings on each day of the symposium: Dr. D. P. Burma, of the Bose Institute, Calcutta, on "Pentose Phosphate Metabolism", Dr. B. K. Bachhawat (Christian Medical College) on "Purification of Enzymes"; Dr. P. M. Bhargava (Regional Research Laboratories, Hyderabad) on "Protein Synthesis" and Dr. T. Ramasarma (Indian Institute of Science) on "Coenzyme Q". P. S. SARMa

\title{
NATIONAL VEGETABLE RESEARCH STATION
}

\section{NEW LABORATORY BUILDING}

$\mathrm{T}$ HE new laboratory building of the National Vegetable Research Station was officially opened on October 23 by H.R.H. The Duke of Edinburgh. The decision to establish the Station was taken after the Second World War because of a continuing need to encourage vegetable production in Great Britain, and the Agricultural Research Council is now responsible for government grant-aid to finance the Station and for the general supervision of its scientific programme.

The new building marks the culmination of ten years development from the time when the director, Dr. J. Philp, took over 280 acres of land at Wellesbourne, near Warwick, in September 1949. Initially the site had no electricity, roads or suitable water supplies, and the only buildings were three small cottages and a few farm buildings. Building restrictions in the early years severely hampered development and the research staff had to be housed temporarily in old service huts, while Dutch light structures served as temporary glasshouses.
The new laboratory building was designed by $\mathrm{Mr}$. F. W. Holder, chief architect of the Ministry of Agriculture, Fisheries and Food, and has a total floor area of 33,800 sq. ft. Besides laboratories and offices it contains a library, lecture room and committee room, and the basement has space for the future provision of controlled-environment chambers. The construction uses pre-cast concrete frame and floors with external curtain-walling of insulated plastic and some brickwork, the roof being of copper. The Station also has about a half-acre of glasshouses used for pot-experiments in research projects, a packing shed, implement shed, farm stores and buildings for livestock. 170 acres are served by underground irrigation mains with a borehole for the water source.

The site at Wellesbourne is central for the country as a whole and the soil and climate are suitable for vegetable production, being similar to those in the nearby Vale of Evesham, an important horticultural area. The area of 280 acres, to which 95 acres have 


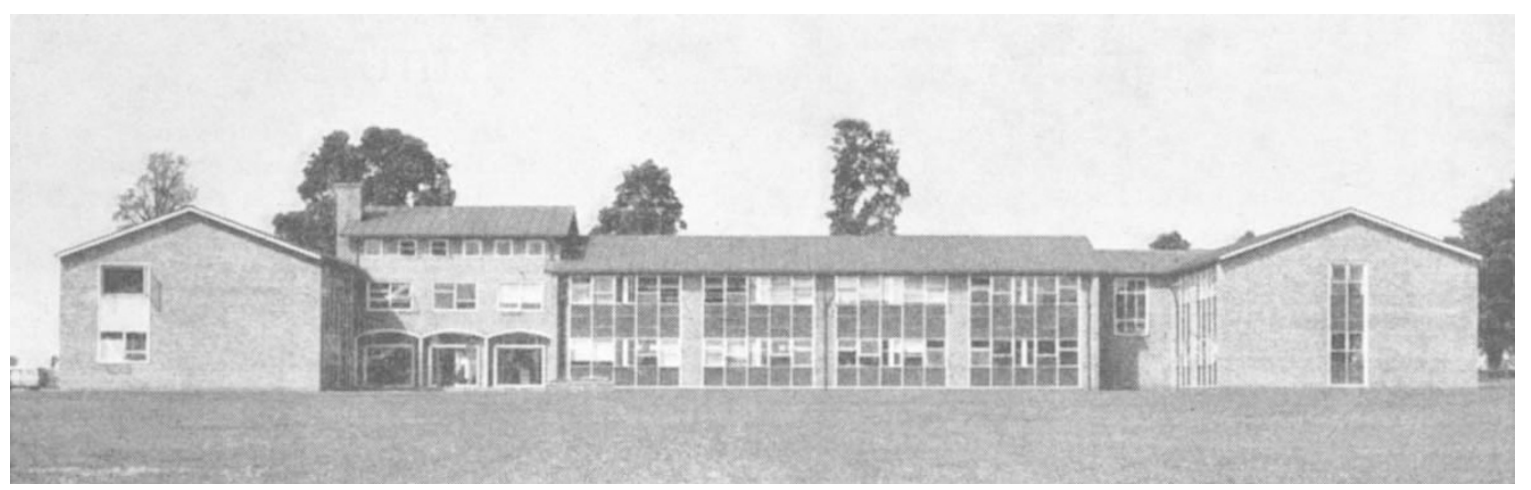

Fig. 1. New laboratories of the National Vegetable Research Station

recently been added, allows a farm unit to be run in conjunction with the experimental vegetable crops and is large enough to provide the isolation necessary for some of the research work. In addition, there is a sub-station at Paglesham, Essex, with an area of 150 acres, which is chiefly used for the multiplication of seed stocks.

All vegetable crops grown in the open and in cold frames, except potatoes, come within the purview of the Station, and its work is organized under eight sections: plant breeding; chemistry; physiology; irrigation; entomology; pathology ; weed control ; statistics.

Long-term experiments with a rotation of vegetable crops are now in their sixth year. The treatments comprise organic and inorganic fertilizers, time and frequency of application of nitrogen, and methods of soil cultivation. Growth studies are being made on some of the crops in these experiments to obtain information on the stages of growth most affected by fertilizers ; the weed populations and soil-moisture characteristics of the soils under different cultivation methods are also being investigated. Dung has been shown to exert a marked influence on growth during the very small seedling stage.

Plant-breeding is carried on at a practical level with the production of improved varieties of vege tables, and at a more fundamental level with the application and development in vegetable crops of breeding methods as such. The method of inbreeding to attain uniformity followed by crossing to restore vigour, used so successfully in maize, has been applied to brussels sprouts, and hybrids with yields 40 per cent above the parent strains have been produced. The backcross technique is being used for the introduction of winter hardiness into an otherwise satisfactory quick-freeze variety of pea. In the diœcious species, asparagus, where the male plant is commercially desirable and usually heterogametic, isolation of homogametic male plants has produced strains giving all-male progeny on crossing.

Entomological research is mainly concentrated on the carrot fly, the cabbage-root fly and the lettuceroot aphid. Ecological work on the effect of insecticides on the balance between the cabbage-root fly and its predators has shown that the balance can be tipped in favour of the pest by indiscriminate broadcast application of insecticides. The use of insecticides against carrot fly raises problems of off-flavours in the crop and of the possible build-up of insecticides in the soil. Extensive testing tests have been carried out at the Station with carrots to assess the effect of insecticides on their flavour. A technique which has been developed for the assay of insecticide residues in the soil enables concentrations of dieldrin as low as 0.05 p.p.m. of soil to be measured.

The diseases of vegetable crops are as diverse as the crops themselves. The silvering disease of red beet, which is bacterial, has been successfully controlled with streptomycin. Fungal diseases include the long-known club root of brassicas and the relatively new crook-root disease of watercress ; new fungicidal techniques give hope of controlling both these, while the prevention of virus diseases in watercress and lettuce is being sought through the production of clean stocks. The development of resistant varieties by selection and breeding techniques is being tried for parsnip canker and Didymella stem rot of tomatoes.

Work on the irrigation of vegetables has been primarily concerned with the most efficient use of water. Moisture-sensitive periods during growth have been found to exist with some vegetable crops, and at these periods irrigation has its maximum effect, while at others it does not produce an economic response. Work has been started on the relationship between water and nutrient uptake in the root system and on the use of additives to irrigation water.

The newer residual herbicides are being tested for suitability on a wide range of vegetable erops, and work has recently started on the nature and extent of the damage to vegetable crops caused by the drift of spray from herbicides used on neighbouring agricultural crops. The effects of weeds are also being studied in two other aspects: the unevenness of weed distribution has been shown to be partly responsible for field-plot variation in the yields of experimental crops, and the reduction in crop yields caused by weeds has been found to be affected by the spatial arrangement of the crop plants. Suitable mathematical models to describe the growth of some crop plants are being sought, with the view of improv. ing the interpretation of treatment-year interactions in long-term experiments.

On the practical side, the Station maintains close links with the National Agricultural Advisory Service, and is fortunate in being able to make use of the experimental horticulture stations of this body for the further testing of experimental findings under a wider range of conditions. On the academic side, an arrangement with the University of Birmingham enables postgraduate work carried out at the Station to be recognized for the purpose of obtaining internal higher degrees of the University.

J. A. NeEDER 